\title{
AOR
}

Selected Papers of \#AolR2020:

The $21^{\text {st }}$ Annual Conference of the

Association of Internet Researchers

Virtual Event / 27-31 October 2020

\section{\#UNMASKEDSELFIESINSOLIDARITY: FROM SELF<IE> CARE TO COLLECTIVE CARE-AFFECTIVE ARTIVISM, NETWORKED BELONGING AND MOBILE MEDIA PARTICIPATORY ART.}

\author{
Klare Lanson \\ RMIT University

\section{Short abstract}

Contemporary mobile media affords new insights into the social, critical, cultural and creative practice methods. With the continual rise of social practice in art which sees the "social" and "experience" as the medium, smartphones have become an increasingly important device for information dissemination, collective dialogue and poetic expression. This paper considers these insights through the lively and multivalent discussion of participatory art project entitled \#UnmaskedSelfiesinSolidarity (2020) as case study. It is situated within the community of RMIT University international students, local students, staff and friends during the initial outbreak of the current pandemic COVID-19, a global health event that has had significant socio-cultural, economic, and political impacts. It employs one of the most pervasive barometers of popular culture today, the selfie.

Moving through related topics such as facial recognition and digital parenting, the \#UnmaskedSelfies team recognise that now more than ever, we need transformative and socially engaged work to engage in collective care. In essence, this project has created an affective listening network to make the unheard heard, to voice personal concerns, and to show empathy for the broader community affected by this global health crisis. \#UnmaskedSelfies openly supports international students caught in the crossfire of strict new travel restrictions imposed by the Government. We critically reflect on the construct of corporatized social media platforms used for public art projects and how art is a socially transformative process, through its messages of care alongside messages from Chinese students suffering anxiety and isolation, waiting for the travel bans to be lifted, a tempering of the stigma and racism accompanying the coronavirus event here in Australia.

Lanson, K. (2020, October). \#UnmaskedSelfiesinSolidarity: From Self<ie> Care to Collective CareAffective Artivism, Networked Belonging and Mobile Media Participatory Art. Paper presented at AolR 2020: The 201 ${ }^{\text {th }}$ Annual Conference of the Association of Internet Researchers. Virtual Event: AolR. Retrieved from http://spir.aoir.org. 


\section{Long abstract}

Contemporary mobile media affords new insights into social, critical, cultural and creative practice methods. With the continual rise of social practice in art which sees the "social" and "experience" as the medium, smartphones have become an increasingly important device for information dissemination, collective dialogue and poetic expression. The methodology of creative practice research playfully disrupts, innovates on, and extends the ways in which knowledge making and transmission can be understood (Farman 2014; Hjorth 2016; Hjorth, de Souza e Silva, and Lanson 2020). These everyday interventions can be framed in terms of broader urban art movements such as the Situationist International (de Souza e Silva 2011 [2004]).

The ubiquity of mobile media inside and outside traditional art spaces has also influenced how contemporary art is received, represented and understood new ways of making art through social media spaces. This can be understood as a borderless form of mobility, where relationships of power and visibility over who moves and who is able to move is at stake (Hannam, Sheller and Urry 2006), as is the case with COVID-19. Mobile media art therefore extends audiences and enables dynamic reinforcement of digital humanities research projects regarding issues such as collective care.

This paper considers these insights through the lively and multivalent discussion of a participatory art project entitled \#unmaskedselfiesinsolidarity (2020) as case study, which highlights the importance of practicing collective forms of care as care at a distance (Pols 2012; Hjorth et al. 2020). It does this through affective and creative use of mobile and social media platforms to activate the experience of social belonging, care and wellbeing. Engaging hundreds of contributions in just a few weeks, this socially engaged artwork is situated within the online and physical spaces of RMIT University in the heart of Melbourne, Australia. The project was located within the community of international students, local students, staff and friends during the initial outbreak of the coronavirus in Wuhan, China, a global health event that has had highly significant sociocultural, economic, and political impacts. It employs one of the most pervasive barometers of popular culture today, the selfie.

Online activity through networked digital publics have long pointed to social media engagement (van Dijck 2013; Hjorth and Hinton 2019), employing collective forms where "we are activated and sustained by feelings of belonging and solidarity, however fleeting or permanent those feelings may be" (Papacharissi 2014, 9). Designed as a set of action strategies including social media and public paste ups, this paper critically reflects on the project \#unmaskedselfiesinsolidarity to consider how participatory art can be a socially transformative process, through its messages of care alongside messages from Chinese students suffering anxiety and isolation, waiting for the travel bans to be lifted, a tempering of the stigma and racism that has accompanied the coronavirus event here in Australia.

Co-led by a team of artist researchers at RMIT University: staff Dr Marnie Badham and Dr Tammy Wong Hulbert (art) and PhD students Klare Lanson and Isabella Capezio 
(media \& communication), Ye (Sherry) Lui (art), and Wilson Yeung (architecture \& design), it resonates the mobilisation of social activist projects to encourage messages of care and solidarity through the phenomenon of the selfie and related hashtag \#unmaskedselfiesinsolidarity. Selfies, when activated through collective processes such as hashtagging, can affectively problematise socio cultural issues, providing visibility and access to a range of people that may be subject to inequalities based on race, gender or sexuality, such as for projects \#blacklivesmatters and the \#metoo movement. A blurring of art and activism within selfie making on social media platforms like the public Facebook Group, Weibo, WeChat and Instagram used in \#unmaskedselfiesinsolidarity allows for the private bodies currently in COVID-19 lockdown mode to be heard around the affective atmospheres of social isolation.

Paul Frosh contemplates the role of social media tagging beyond archival purposes. The entanglement of image, names, bodies and networks exist as a highly social and embodied performance-a continuous cycle of making communities, where tagging is "a profoundly poetic procedure for populating and disclosing worlds ... by continually assembling multiple others in the confirmation of one's existence as a body" $(2019,95)$. The more collectively created hashtag alongside the tagging of individuals in digital imagery also assumes a stance where platform connectivity takes precedence over matters of personal privacy. This complicates our engagement with digital media-with social and highly networked collective activity comes responsibility and ethical thinking around why we choose to do it, how we practice the doing of data and our perceived authority to do so.

Global pandemic conditions have also further heightened the discrimination and distrust of the Chinese Government and citizens, further impacting on the diaspora and people of Asian appearance in Australian society and beyond. With worsening pandemic conditions in the USA, these larger global influences, increased fear and anxiety in society due to abnormal socio-economic conditions, have created the context for increased stigma, racism and prejudice towards people of Chinese heritage. Our smartphones acted as creative co-conspirators, enacting the collective role of sensemaking, communicating with others through public space, and documenting how we move in and through the world. This experience provides evidence that the subjective self $<i e>$ is performative, multidimensional and complex. This paper proposes the understanding of the selfie as a mediated and networked public art space.

Once known as 'netizens' (Clark 2012)-a term dating back to 1984, popularised in mid90s China and used to describe global citizens intent on using the internet to improve social relationships-\#unmaskedselfiesinsolidarity, as a transnational project, is performed by a team of 'artivists'. This fertile merge of art and social activism takes full advantage of our social and digital world, framed as a form of resistance and "often considered in relation to a model of conflict" (Toft 2016, 61). With over 700 million users in China, the term 'netizen' is now deeply contested as 'it implies that political views in China exist solely online, away from the confines of regular society" (Schiavenza 2013). Interestingly, new technological developments such as facial recognition software have been recently adopted by companies in China "announcing their technology can now identify people even when they're wearing facemasks" (Li 2020, n.p.). 
Using masks as performative objects within \#unmaskedselfiesinsolidarity was also seen to be a mode of protection for participants in terms of everyday forms of data privacy and surveillance. Many who wished to protect themselves from modes of facial surveillance, especially Asian participants, chose to create a masked selfie, as opposed to an unmasked one. China, like many countries around the world, certainly utilises mass surveillance technology that leads to unwanted intrusions of privacy. Especially in light of COVID-19, where it was reported that facial recognition software used in China has now further developed its Al capacity to provide a "full range of epidemic prevention information such as body temperature, mask-wearing status, and employee identity" (Li 2020 , n.p.). However, when thinking metaphorically, although many contributed selfies were indeed masked, the situated action of participating in our collective project could very well be seen as visible enough.

This project has also created an affective listening network, to show empathy for the broader community affected by this global pandemic. To date, findings have notably highlighted a form of parental modeling for those advocating a more balanced approach to digital parenting (Clark 2013; Lim 2016; Ryan Vickery 2017; Plunkett 2019; Lim 2020 ), due to the related issue of increased racial vilification in schools and then remote learning practices due to the coronavirus outbreak and subsequent lockdown mode. Many children chose to upload selfies alongside their parents to protest unwanted racism.

Being highly affective, the selfie is both a mediated digital object and a gestural practice of communication (Senft and Baym 2015; Warfield et al. 2016; Kuntsman 2017; Tiidenberg 2018). We understand \#unmaskedselfiesforsolidarity to be more than simply an archive of self-expression or a hashtag, but as an embodied digital composite of conceptual and performative parts that act as a socially engaged arts methodology. It assumes a commitment equally to social aims and aesthetic interests. Selfie making can be understood as an act of self-determination and representation requiring active reflexivity, at the same time expressing the intention to contribute to a live shared narrative.

Many patterns were discovered within the choices made by participants in relation to both the messages and the selfies created. As selfies were posted throughout the project's duration, interesting connections were revealed. For example, the importance of morethan-human feelings of care within the home was highlighted as many participants chose to share their selfie moment with their pet companions. Animals are recognised as an important part of the home dynamic, an entanglement of intimacy and kinship (Hjorth, Richardson, and Balmford 2016), it makes sense that pet relationships are a type of reciprocal care. To share and perform a selfie with a pet-or even 'help' our pets create a selfie-heightens our sense of well-being during periods of social isolation.

\#unmaskedselfiesinsolidarity offered a more complex, playful and nuanced counter to prejudiced perspectives by creating a public platform for individual exchange. Fears of racism, mistrust, and isolation were expressed by international students who participated. They expressed the desire to be viewed as individuals beyond racial stereotypes. Our project captured the early stages of this difficult period of COVID-19 by working on a local scale with our own student community and played out to reflect a 
national crisis impacted by greater international relationships. Through collaborative, creative, directed and nominal forms of participation (Huelguera 2011), these early personal, emotional expressions by our students and the wider community, was an indication of what was to come, as Australia went into lockdown.

NB: The short digital essay created for online presentation at AolR2020 is based on a reflective conversation in August 2020 in relation to \#unmaskedselfiesinsolidarity, initiated and created by Klare Lanson, with Dr Tammy Wong Hulbert and Dr Marnie Badham.

\section{References}

Artivism collective. n.y. "What is artivism for?", Artivism website, n.d.

Clark, Lynn Schofield. 2013. The Parent App; Understanding Families in the Digital Age. New York: Oxford University Press.

Clark, Paul. 2012. Youth Culture in China: From Red Guards to Netizens. Cambridge University Press.

de Souza e Silva, Adriana. 2011 [2004]. "Art by Telephone: From Static to Mobile Interfaces." In The Mobile Audience: Media Art and Mobile Technologies, edited by Martin Rieser, 67-80. Amsterdam: Rodopi.

Dijck, José Van. 2013. The Culture of Connectivity a Critical History of Social Media. New York: Oxford University Press.

Farman, Jason (ed). 2014. The Mobile Story: Narrative Practices with Locative Technologies. New York: Routledge.

Frosh, Paul. 2019. The Poetics of Digital Media. Cambridge, UK: Polity.

Hannam, Kevin, Sheller, Mimi, and John Urry, "Editorial: Mobilities, Immobilities and Moorings," Mobilities 1, no. 1 (2006): 1-22, DOI: 10.1080/17450100500489189.

Hjorth, Larissa. 2016. "Mobile Art: Rethinking Intersections between Art, User Created Content (UCC), and the Quotidian". Mobile Media \& Communication, 4(2): 169-85, DOI: 10.1177/2050157915619210.

Hjorth, L., Richardson, I., and Balmford, W. 2016. "Careful surveillance and pet wearables: at home with animals". The Conversation, September 5.

Hjorth, Larissa, Ohashi, Kana, Sinanan, Jolynna, Horst, Heather, Pink, Sarah, Kato, Fumitoshi, and Baohua Zhou. 2020. Digital Media Practices in Households: Kinship Through Data. Amsterdam: Amsterdam University Press. DOI: 10.5117/9789462989504. 
Hjorth, Larissa, da Souza e Silva, Adriana, and Klare Lanson (eds.). 2020. The Routledge Companion to Mobile Media Art. London; New York: Routledge.

Kuntsman, Adi. (ed). 2017. Selfie Citizenship. Cham, Switzerland: Palgrave Macmillan.

$\mathrm{Li}$, Jane. 2020. "China's facial recognition giant says it can crack masked faces during the coronavirus". Quartz, February 18.

Lim, Sun Sun. 2016. "Through the Tablet Glass: Transcendent Parenting in an Era of Mobile Media and Cloud Computing." Journal of Children and Media 10 (1): 21-29. DOI: 10.1080/17482798.2015.1121896.

. 2020. "Mobile Communication and Transcendent Parenting." In Transcendent Parenting: Raising Children in the Digital Age, 134-54. New York: Oxford University Press.

Papacharissi, Z. 2014. Affective Publics: Sentiment, Technology, and Politics. New York: Oxford University Press.

Perpitch, Nicolas. 2020. "Coronavirus travel ban hits Australian universities, schools as Chinese students stranded overseas", ABC News, 19 Feb.

Plunkett, Leah A. 2019. Sharenthood: Why We Should Think Before We Talk About Our Kids Online. Cambridge, MA: The MIT Press.

Pols, Jeannette. 2012. Care at a Distance on the Closeness of Technology. Care \& Welfare. Amsterdam: Amsterdam University Press.

Ryan Vickery, Jacqueline. 2017. Worried About the Wrong Things: Youth, Risk, and Opportunity in the Digital World. Cambridge, MA; London: The MIT Press.

Schiavenza, Matt. 2013. “Enough with the word 'Netizen'”, The Atlantic, Sept 25.

Tiidenberg, Katrin. 2018. Selfies: Why we love (and hate) them (First ed.). Bingley: Emerald Publishing Limited.

Toft, Tanya. (2016). "What Urban Media Art can Do". In What Urban Media Can Do: Why, When, Where \& How, edited by Susa Pop, Tanya Toft, Nerea Calvillo and Mark Wright, 50-65. Stuttgart: Avedition.

Warfield, K., Cambre, C., and Abidin, C. (2016). "Introduction to the Social Media + Society Special Issue on Selfies: Me-diated Inter-faces", Social Media + Society, April-June 2016, p1-5. DOI: 10.1177/2056305116641344. 